\title{
Acute Visual Loss as the Presenting Complaint of Hereditary Hemorrhagic Telangiectasia
}

Karissa L. Hackelton, MD

The complaint of new floaters in the visual field is a common one in the practice of Family Medicine. Whereas these can represent serious problems such as a detached retina, it can also be representative of normal aging of the vitreous humor. In a young patient with this complaint, we were surprised to find that this occurred because of a branch retinal artery occlusion that led to the diagnosis of hereditary hemorrhagic telangiectasias, also known as Osler-Weber-Rendu syndrome. It was an uncommon presentation of an uncommon disease. Knowing more about this disease could help family practitioners diagnose it earlier and be able to screen family members appropriately. (J Am Board Fam Med 2006;19: 637-40.)

\section{Case Report}

A 22-year-old white male without significant past medical history presented by phone with the complaint of a 24-hour history of vision loss in his right eye described as a large floater in the center of vision. He denied any other complaints, including headache, nausea, vomiting, diarrhea, fever, dizziness, loss of consciousness, seizures, parasthesias, tearing, or eye pain. Other than the loss of vision, he felt fine. Patient did report being hit in the head approximately 2 weeks before onset of symptoms. He did have a prior history of smaller floaters but chose to seek medical advice after losing a sizable portion of his vision. Family history was significant for frequent nosebleeds in his father and brothers, as well as cerebrovascular accident (CVA) at age less than 60 years in his paternal grandmother, who also complained of nosebleeds. On further questioning, his paternal aunt and great-grandmothers also suffered early deaths (less than 50 years of age), possibly from CVA. Social history was negative for tobacco, alcohol, and drug use. The patient was advised to see an ophthalmologist as soon as possible for evaluation. He did so and was found to

This article was externally peer-reviewed.

Submitted 13 February 2006; revised 12 May 2006; accepted 15 May 2006.

From the Chesterfield Family Practice, Richmond, VA.

Conflict of interest: none declared.

Corresponding author: Karissa L. Hackelton, MD, Chesterfield Family Practice, 2500 Pocoshock Place, Richmond, VA 23235 (E-mail: hackkar1@aol.com). have a branch retinal artery occlusion of the right eye causing a scotoma.

The patient was subsequently seen by his family practioner and the workup for an embolic source began with a normal electrocardiogram, transthoracic echocardiogram, and carotid dopplers. Complete blood count was done, and he was revealed to have a hemoglobin of $23.5 \mathrm{~g} / \mathrm{dL}$ (normal $12 \mathrm{~g} / \mathrm{dL}$ to $18 \mathrm{~g} / \mathrm{dL}$ ), hematocrit of $65.1 \%$ (normal $37 \%$ to $51 \%$ ), mean corpuscular volume of $100 \mathrm{fL}$ (normal $80 \mathrm{fL}$ to $97 \mathrm{fL}$ ), red cell distribution width of $14.8 \%$ (normal $11.5 \%$ to $14.5 \%$ ), platelets of $205 \mathrm{~K} / \mu \mathrm{L}$ (normal $140 \mathrm{~K} / \mu \mathrm{L}$ to $440 \mathrm{~K} / \mu \mathrm{L}$ ). This was repeated with confirmation of results. On examination, he was noted to have a central cyanosis that had been present for several years, his mother noting that people often remarked on the color of his lips. His oxygen saturation was $86 \%$ on room air.

With these abnormalities, he was admitted to the hospital. Initial blood gas measurements were obtained on $4 \mathrm{~L}$ of oxygen. Results were as follows: $\mathrm{pH}$ 7.48, $\mathrm{pCO}_{2}$ 28.7, $\mathrm{pO}_{2}$ 49. Chest films showed a rounded density just below the left hilum. The pulmonologist suspected this finding was likely a large pulmonary arteriovenous malformation (PAVM) causing a right to left shunt that resulted in the patient's hypoxemia. This, along with the family history of frequent nosebleeds, led to the diagnosis of hereditary hemorrhagic telangiectasias (HHT). The patient next underwent CT of the chest which found approximately 14 bilateral PAVMs, the largest in the left lingula being $5 \mathrm{~cm}$ in 
diameter to less than $1 \mathrm{~cm}$. CT of the head was negative, as was MRI of the brain. An ultrasound of the abdomen did not show any abnormalities. $\mathrm{He}$ subsequently underwent embolization of the PAVMs twice while hospitalized which improved his oxygen saturation.

Since his discharge from the hospital, he has undergone AVM embolization again, and has been referred to an HHT treatment center. His vision has improved to the point that he no longer notices the large defect in his visual field. He is back to work and leading a normal life. Because of his diagnosis and the strong familial component, his father and brothers have had evaluations as well, all whom complained about frequent epistaxis, although the lack of epistaxis would not have precluded evaluation. Whereas his father's MRI/MRA of the head were normal, his CT chest showed a small PAVM. His brothers all have been found to have one to 4 PAVMs, whereas one brother additionally has a cerebral AVM as well. One of his brothers did require PAVM embolization.

\section{Discussion}

HHT is an autosomal dominant disorder characterized by telangiectasias of multiple organ systems, including the skin and mucus membranes, and visceral lesions involving the gastrointestinal, pulmonary, and neurologic systems. It affects approximately half a million people in the world, although prevalence varies depending on geographic area and source (estimates from $1 / 3,500$ to 1 to $2 / 100,000)$. As defined by the HHT Science Advisory Board meeting in Curacao, clinical diagnostic criteria are:

1. Epistaxis that is spontaneous and recurrent

2. Telangiectasias in multiple sites

3. Visceral lesions such as AVM in various organ systems

4. Family history of a first-degree relative with HHT

Three of these criteria indicate a diagnosis of HHT, whereas 2 criteria give a possibility, and less than 2 is an unlikely diagnosis. ${ }^{1}$ Prevalence of these manifestations are presented in Table 1. There have been 2 types of HHT described: HHT-1 and HHT-2, which occur from mutations in the ENG and ALK-1 genes, respectively. HHT-1 tends to
Table 1. Features of HHT

\begin{tabular}{|c|c|c|}
\hline Features of HHT & $\begin{array}{c}\text { Prevalence } \\
(\%)\end{array}$ & Source \\
\hline Epistaxis & 90 & Gallitelli et al. ${ }^{6}$ \\
\hline $\begin{array}{l}\text { Mucocutaneous } \\
\text { telangiectasias }\end{array}$ & 75 & Begbie et al. ${ }^{16}$ \\
\hline $\begin{array}{l}\text { Conjunctival telangiectasias } \\
\text { (or other ocular } \\
\text { involvement) }\end{array}$ & 45 to 65 & Georgiou et al. ${ }^{10}$ \\
\hline PAVM & 38.7 & Post et al. ${ }^{5}$ \\
\hline CAVM & 55 to 27 & Fiorella et al ${ }^{9}$ \\
\hline HAVM & 30 & Begbie et al. ${ }^{16}$ \\
\hline
\end{tabular}

have a more severe presentation, with more frequent PAVM and CAVM, while HHT-2 has more frequent hepatic AVMs (HAVM). ${ }^{2}$

Epistaxis is caused by telangiectasias of the nasal mucosa, and is the most common manifestation of HHT. It typically presents by age 21 , often appearing as young as age 10 , but can be absent. The nasal telangiectasias, however, appear in more than $90 \%$ of patients although only $50 \%$ to $80 \%$ of patients have recurrent epistaxis. Epistaxis secondary to these nasal telangiectasias can be so severe as to require blood transfusions or oral iron. ${ }^{3}$

Telangiectasias normally appear in the mucosa or the skin. Whereas the nasal mucosa is the most common, they can also appear in nailbeds, conjunctiva, oral mucosa, GI tract, or anywhere on the skin. The skin telangiectasias appear later in life, increasing in number and size with age. GI telangiectasias are most often found in the stomach and duodenum, less often in the colon. All these do tend to bleed easily, especially with increasing age, and can again be associated with the need for transfusion. ${ }^{4}$

Pulmonary complications of HHT are an important aspect of the disease. Pulmonary AVMs occur in $20 \%$ of patients. Approximately $70 \%$ of all PAVMs occur in patients with HHT, so evaluation of this disease should occur if PAVM is found in an undiagnosed patient. The right-to-left shunt associated with PAVM can result in hypoxemia and paradoxical emboli, or even and increased prevalence of migraine. ${ }^{5}$ There is also the risk of PAVMs or telangiectasias bleeding, which can lead to hemoptysis if there is bleeding into a bronchus, or hemothorax if there is bleeding into the pleural cavity. ${ }^{6}$ However, as many as $50 \%$ of patients are asymptomatic, even if physical signs of hypoxemia are present. ${ }^{2}$ 
Neurologic manifestations occur in approximately one third of patients with HHT. These can range those related to PAVM such as transient ischemic attacks, CVAs, or brain abscesses, or a more direct involvement such as cerebral AVM. ${ }^{7}$ From the literature, it seems that there is a higher risk of neurologic involvement that is related to PAVM, either by ischemia or paradoxical embolization than other causes. ${ }^{8}$

In the GI tract, HAVM can be found. These are generally asymptomatic because of compensation of the shunting by the heart. Symptoms that may occur include dyspnea, fatigue, or high output congestive heart failure, and can be related to the AVM itself, or portal hypertension which can lead to splenomegaly, varices, or an enlarged portal vein. Hepatic embolization is associated with significant morbidity and mortality, so it is not currently recommended as treatment for HAVM. ${ }^{9}$

Ophthalmalogic manifestations of HHT generally occur as conjunctival telangiectasias, similar to the common mucosal lesions in the disease. Intraocular lesions are typically rare and are consistent with retinal vascular malformations including a case of choiroidal telangiectasia. ${ }^{10}$ In addition, there is a case report that presents a case of HHT causing retinopathy similar to that of diabetic retinopathy. ${ }^{11}$ Another reports the diagnosis of HHT made by the presence of a conjunctival telangiectasia. ${ }^{12}$ A study of patients with HHT, looking for ocular manifestations revealed conjunctival telangiectasias as well as retinal vascular malformations less commonly. ${ }^{13,14}$ There is a case report of amaurosis fugax resulting from pulmonary arteriovenous fistula, but was not related to HHT. ${ }^{15}$ No reports of embolic ophthalmologic complications were found.

Because of the likely complications involving bleeding, including epistaxis and GI bleeding, patients should be monitored closely for anemia. Patients should be screened for pulmonary AVM starting at age 10 with contrast echocardiography, helical CT of the chest every 5 years or other screening method. Children younger than age 10 should be screened with pulse oximetry every 1 to 2 years if they are at risk for HHT. Anyone found to have a pulmonary AVM should receive antibiotic prophylaxis for dental or other surgical procedures. MRI of the brain should be performed at least once to evaluate for cerebral AVM. This can be done in childhood, as cerebral AVMs are present early on and do not spontaneously form. ${ }^{15}$

In our patient's case, his large pulmonary AVM caused a right-to-left shunt that resulted in hypoxemia. The longstanding hypoxemia caused his polycythemia. Interestingly, he did not suffer from epistaxis as frequently as his brothers or father, which possibly contributed to his polycythemia. The etiology of the branch retinal artery occlusion could either be related to the hyperviscosity from his severely elevated hemoglobin level, or paradoxical embolism from the extremely large pulmonary AVM. A MEDLINE review of the literature did not reveal any reports of retinal artery occlusion related to embolism from HHT.

We thank Richard Hoffman, MD; Walter Waugh, MD; Angela Middleton, MD; and Juan Astruc, Jr., MD.

\section{References}

1. Shovlin CL, Guttmacher AE, Buscarini E, et al. Diagnostic Criteria for hereditary hemorrhagic telangiectasia (Rendu-Osler-Weber syndrome). Am J Med Genet 2000;91:66-7.

2. Letteboer TGW, Mager JJ, Snijder, et al. Genotypephenotype relationship in hereditary haemorrhagic telangiectasia. J Med Genet 2006;43:371-7.

3. Shovlin CL, Letarte M. Hereditary Hemorrhagic Telangiectasia and pulmonary arteriovenous malformations: issues in clinical management and review of pathogenic mechanisms. Thorax 1999;54:714-29.

4. Haitjema T, Westermann CJJ, Overtoom TTC, et al. Hereditary hemorrhagic telangiectasia (OslerWeber-Rendu disease) new insights in pathogenesis, complications, and treatment. Arch Intern Med 1996;156:714-19.

5. Post MC, Letteboer TGW, Mager JJ, et al. A pulmonary right-to-left shunt in patients with hereditary hemorrhagic telangiectasia is associated with an increased prevalence of migraine. Chest 2005;128: 2485-9.

6. Gallitelli M, Pasculli G, Fiore T, et al. Emergencies in hereditary haemorrhagic telangiectasia. Q J Med 2006;99:15-22.

7. Sobel D, Norman D. CNS Manifestations of hereditary hemorrhagic telangiectasia. AJNR 1984;5:56973.

8. Moussouttas M, Fayad P, Rosenblatt M, et al. Pulmonary arteriovenous malformations: Cerebral ischemia and neurologic manifestations. Neurology 2000;55:959-64.

9. Fiorella ML, Ross DA, White RI, et al. Hereditary haemorrhagic telangiectasia: state of the art. Acta Otorhinolaryngol Ital 2004;24:330-6. 
10. Georgiou T, Qureshi SH, Chakrabarty A, Noble BA. Choroidal telangiectasia in a patient with hereditary hemorrhagic telangiectasia. Eye 2002;16:92-4.

11. Davis DG, Smith JL. Retinal Involvement in hereditary hemorrhagic telangiectasia. Arch Ophthal 1971;85:618-23.

12. Knox FA, Frazer DG. Ophthalmic presentation of hereditary hemorrhagic telangiectasia. Eye 2004;18: 947-9.

13. Brant AM, Schachat AP, White RI. Ocular manifestations in hereditary hemorrhagic telangiectasia
(Rendu-Osler-Weber disease). Am J Ophthal 1989; 107:642-6.

14. Yamakuchi M, Tanaka S, Tomosugi T, et al. Pulmonary arteriovenous fistula manifesting as amaurosis fugax. Neurol Med Chir (Tokyo) 2000;40:264-7.

15. Guttmacher AE, Marchuk DA, White RI. Hereditary hemorrhagic telangiectasia. N Engl J Med 1995; 333:918-24.

16. Begbie ME, Wallace GMF, Shovlin CL. Hereditary hemorrhagic telangiectasia (Osler-Weber-Rendu syndrome): a view from the 21 st century. PMJ 2003; 79:18-24. 